\title{
Policy-based instructional reform in early education: how US Head Start teachers perceive instructional mandates
}

Jennifer Wallace Jacoby ${ }^{1 *}$ and Nonie K. Lesaux ${ }^{2}$

*Correspondence:
jacoby@mtholyoke.edu
${ }^{1}$ Department of Psychology
and Education, Mount
Holyoke College, South
Hadley, MA 01075, USA
Full list of author information
is available at the end of the
article

*Correspondence: jacoby@mtholyoke.edu Department of Psychology and Education, Mount Hadley, MA 01075, USA is available at the end of the article

\begin{abstract}
The goal of this study was to investigate how early childhood teachers reported responding to the instructional mandates they received. To answer our research questions, we completed semi-structured interviews with 20 early childhood teachers and coded their responses. The participating teachers were recruited from a large Head Start agency in the United States. We found that Head Start teachers reported feeling caught between two competing priorities: the priority the program placed on compliance with instructional routines and the priority the teachers placed on addressing children's social, emotional, and behavioral needs. Essentially, teachers perceived that they must demonstrate compliance to the program's instructional mandates first and foremost. Furthermore, they perceived that the program's instructional coaches were monitoring their compliance with the mandates. As a result of this workplace context, the Head Start teachers reported that they did not feel permitted to alter the program's required instructional procedures. The implications for policy and research are discussed.
\end{abstract}

Keywords: Early childhood education, Policy, Bilingual children, Social and emotional skills, Preschool, National curriculum, Head Start, Qualitative research

\section{Background}

Globally, there has been increasing recognition of the importance of early childhood care and education programs as a mechanism by which to support children's healthy development (e.g., Flottman and Page 2012; Heckman and Masterov 2007; May 2008). Accordingly, many of the world's economic and educational institutions have invested in the expansion of early childhood education programs for all children. For example, in Finland where, historically, education has been compulsory only from age 7 and upward, compulsory education has been expanded to include 6 year-olds in the national preschool program. Furthermore, Finland transitioned oversight of its early childhood education programs from the Social Affairs and Health Ministry to the Ministry of Education (Chandler 2014). Similarly, in many other countries, including New Zealand (Taguma et al. 2012) and Australia (Flottman and Page 2012), there is a press for expanded early education opportunities. These shifts demonstrate the perceived 
potential and promise of early childhood as a path toward success at the child and societal levels.

In the US, the number of states offering free, universal pre-kindergarten programs for 4 year-olds is on the rise (Gormley and Phillips 2005; Weiland and Yoshikawa 2013). Unfortunately, though, progress has been slow. Nationally, only $41 \%$ of 4 year-olds and $16 \%$ of 3 year-olds were served by government-funded programs in the 2014-2015 school year, which reflects only a $1 \%$ point growth in number of children served since 2010 (Barnett et al. 2016). Though the recent focus on the expansion of early childhood education programs is relatively new among US policy-makers and citizens, there is one government-funded model for preschool that has existed for over 50 years in that country; Head Start is a federally funded and locally administered early care and education program that provides free preschool to children from low-income families. Currently, Head Start programs serve one million children from low-income families across the US (Office of Head Start 2013).

There is a solid foundation of research indicating that Head Start can have long-term, profound positive effects on the lives of children and families by improving numerous social outcomes-such as increasing attendees' chances of going to college, staying out of jail, and avoiding teen pregnancy (Deming 2009). The Head Start Impact Study (US Department of Health and Human Services [DHHS] 2010), which tracked 5000 children-half of whom were randomly assigned to Head Start and the other half who were not assigned to Head Start-through preschool-age into elementary school, found that the program also positively affects children's cognitive development in areas such as vocabulary, math, and early literacy skills. At the same time, critics question the efficacy of the program for developing early academic skills (see Ludwig and Phillips 2008), particularly in light of the Head Start Impact Study finding that many of the academic benefits faded by the end of 1st grade (DHHS 2010). Given the current pressure to improve outcomes for children via high-quality early childhood programs, and the overall mission of the program, Head Start is concerned with improving its ability to be an effective intervention for young children from low-income homes. Additionally, the population of children it serves is increasingly culturally and linguistically diverse, which contributes further complexity to accomplishing the program's goal of creating high-quality learning environments (DHHS 2008). Thus, Head Start is necessarily focused on implementing high-leverage strategies that will improve all children's academic outcomes. These highleverage strategies have included instructional mandates, such as requiring the inclusion of specific teaching routines or adherence to a set curriculum, and demand investigation as to how they are implemented and understood by early childhood teachers-teachers who are often under-valued, minimally trained (Whitebook et al. 2014), and susceptible to turnover (Wells 2015).

Therefore, the present study endeavors to foreground the voices of the Head Start teachers who are held responsible for creating and delivering high-quality learning experiences to the diverse group of young children in their classes by following through on the program's instructional mandates (i.e., delivery of curriculum; implementation of specified teaching routines, and submission of and adherence to lesson plans). Because of the known link between teachers' perceptions of their workplace context and their students' learning (Bryk et al. 2010; Johnson et al. 2012; Ladd 2009), and the lack of such 
research in early education settings, this study begins a conversation about how to use policy and instructional guidelines to best support early childhood teachers. Specifically, in this study, we asked 20 Head Start teachers to describe their decisions about what and how to teach while working within the context of an early education program that is guided by federally mandated instructional policies. The findings shed light on the teachers' perception of their workplace context and yield implications for policy, practice, and research.

\section{Who are Head Start teachers?}

The early childhood education teacher workforce in the US differs from the K-12 (primary and secondary grades) workforce in many ways. Overall, and in comparison to the K-12 system, Head Start teachers-like the broader early educator population-are distinct on a number of characteristics, including professional training, earning potential, and demographics. Specifically, Head Start teachers are paid less for the work they do than public school teachers-even those with the same academic degrees; and because of these low wages, Head Start teachers face economic uncertainty in their personal lives (Whitebook et al. 2014). In general, Head Start teachers and other early childhood educators have less formal education than K-12 teachers (Whitebook et al. 2014), which is an artifact of the reduced level of credentials required for entry into the early childhood education workforce. Of note, the federal reauthorization of Head Start in 2007 stipulated that the number of lead teachers with bachelor's degrees in any given program must be at least $50 \%$ of the lead teaching staff. Most programs have made positive strides toward this goal, however, concurrently with these increases in degree requirements has come an increase in the rate of teacher turn-over in Head Start-possibly because these teachers can make more money in other early childhood programs, such as public prekindergarten, with the same degrees (Kaplan and Mead 2017). At the same time, Head Start actively recruits teachers whose cultural and linguistic background match that of their students (Mancilla-Martinez and Lesaux 2014), which is an asset when serving vulnerable populations, and appear to be more successful in this recruitment effort than other early education programs (Saluja et al. 2002). In these ways-lower overall remuneration, generally lower rates of formal education and credentials, and higher rates of cultural, racial, and linguistic diversity-the early childhood teacher workforce is distinct from the K-12 workforce in the US. And these differences point to potential reasons that their competence and professionalism may be viewed differently than teachers in the K-12 workforce, and to reasons why their voices might be absent from educational research that focuses on policy.

\section{National preschool policies and teachers' responses to them}

Many countries, including Finland, Sweden, Norway, New Zealand, England, Ireland, France, and Greece, have adopted a national curriculum for early childhood. Generally speaking, these national curriculums for early childhood lay out a framework for learning that guides local implementation of each nation's government-funded preschool program (Alvestad and Samuelsson 1999; Flottman and Page 2012; May 2008). Though there is a strong research base in early childhood development to inform the content of such national curriculums, there are only a few prior investigations into the implementation 
of these policy-driven reforms at the preschool-site and -classroom level (e.g., Brodin and Renblad 2015; Bullough et al. 2014; Sofou and Tsafos 2009; Wood 2004). For example, researchers in Sweden found that the majority of the 111 preschool teachers they surveyed felt positively about the content and implementation of the new national preschool curriculum (Brodin and Renblad 2015). The Swedish preschool teachers shared few concerns regarding the implementation of the new curriculum. They did, however, report concern over the curriculum's ability to meet the learning goals for children with special needs and to meet the goals of other stakeholders in the community, such as parents.

In a study with similar aims, Sofou and Tsafos (2009) interviewed 11 early childhood teachers in Greece who were tasked with implementing a newly created national curriculum for preschool. Most of the teachers spoke positively about the child-centered focus of the curriculum, yet all complained about the lack of professional development concerning how to implement the curriculum. Despite supporting the content of the curriculum, the Greek teachers reported feeling uncomfortable with the recipe-like structure of the planning guide that accompanied the curriculum and worried that it might deprofessionalize their work.

Notably, and in contrast to the findings from other national contexts, one prior study with Head Start teachers revealed that recent, global shifts in the importance placed on early childhood education in the US policy context and media manifested in primarily negative feelings about the nature of their work. The researchers attributed Head Start teachers' reported negative feelings to the phenomenon of "work intensification," which stemmed from the "need for teachers to become more sharply focused on the specific instructional goals and to document results" (Bullough et al. 2014, p. 62). Overall, through interviews and surveys, the teachers revealed that the workplace policy context was one that pulled their time toward compliance-related tasks and away from teaching.

Taken together, these studies reveal that early childhood teachers have unique experiences of the national policy contexts that guide their work. Yet, there is still relatively little understanding of how teachers make daily decisions about what and how to teach within these contexts. The relative dearth of empirical work in this area-and at a time when there is increasing attention on expanding free, government-funded preschoolleaves policy-makers, administrators, and teachers with little research to guide their decision-making, particularly in terms of how to ensure that local programs can be responsive to the needs of increasingly diverse populations of children while also demonstrating compliance with mandated instructional guidelines.

\section{Why would Head Start monitor compliance with instructional guidelines?}

One way to bring high-quality instructional practices to scale across the Head Start network, which operates in all 50 states and also in US territories, is to require that all sites use evidence-based curriculums as part of their academic program. Another way is to monitor compliance with a set of instructional routines and strategies. In fact, Head Start asks that their programs demonstrate compliance with both. Specifically, Head Start requires that all agencies follow the national Head Start Program Performance Standards (DHHS 2016), and its federal office mandates that instruction in all preschool classes demonstrate adherence to and utilize a curriculum that reflects compliance with 
these program performance standards. ${ }^{1}$ A question for the field, then, is how these instructional mandates are received and perceived in Head Start classrooms, particularly by teachers. Prior research in the primary and secondary grades in the US system of education has explored how prescriptive teaching practices influence teachers' perceptions of the effectiveness of their workplace, with effectiveness defined as potential for addressing children's learning needs (e.g., Rosenholtz 1989), but there are no similar studies in US preschool education systems.

The use of standardized curriculums to boost the achievement of children from lowincome families is an increasing trend that is seen across the entire US educational system. School districts that are concerned about low test scores and closing the distance in achievement between sub-groups of students may adopt more structured-or scriptedcurriculums in an attempt to standardize teaching (Ede 2006). The argument used to justify adoption of these structured curriculums is that quality can be better supported (e.g., shared language for coaching) and assured when teachers are following the same curriculum (Ede 2006; Parks and Bridges-Rhoads 2012). Moreover, education researchers have established that using a combination of professional supports, such as structured curriculum and professional coaching, can provide a platform upon which early childhood educator skills can be built (e.g., Neuman and Cunningham 2009; Wasik et al. 2006).

One recent and compelling example of the use of a curriculum as a platform for coaching and shared instructional practices comes from the Boston Public Schools prekindergarten project-a public pre-k program that required teachers to use a researchbased curriculum and supported and ensured their consistent use of the curriculum by providing educational coaches. Researchers evaluating this program found that participating children made academic gains across several content areas including language, literacy, and mathematics (Weiland and Yoshikawa 2013). What was missing from this investigation, however, was qualitative data that would illuminate the perceptions and experiences of the teachers who received these instructional mandates.

In the Head Start agency we studied, Education Mentors (Ed Mentors)-administrators who serve as a sort of instructional coach-monitor teachers' compliance with the instructional mandates by reviewing all lesson plans prior to implementation. The Ed Mentors at these Head Start sites are frequently promoted from the rank of teacher into the Ed Mentor position. As Ed Mentors, these women occupy a position in between the teachers and the site director in the organizational hierarchy. The Ed Mentors do not have teaching responsibilities in the classrooms; and their workspaces are located in the administrative offices. In location and position, and by characterization from the classroom teachers, the Ed Mentors are more aligned with the administrators of the program than the teaching staff.

One of the roles and responsibilities of the Ed Mentors in this Head Start program is to review and approve the teachers' lesson plans prior to implementation. The purpose of this lesson plan review is to ensure that they contain the required instructional

\footnotetext{
1 The Head Start Program Performance Standards have just been completely revised and reorganized for the first time since their inception in 1975. Beginning in November 2016, all Head Start programs will be implementing the revised Program Performance Standards.
} 
components and demonstrate compliance with the adopted curriculum. A second purpose is to allow an opportunity for mentoring and support from the Ed Mentors for teachers whose lesson plans may not include the required components. Additionally, the Ed Mentors check in during classroom instructional time to confirm that the teachers are following the schedule and curriculum included in the approved lesson plans. In this way, the Head Start program ensures that their teaching staff is supported to comply with the Head Start Program Performance Standards (DHHS 2016).

\section{Present study}

In the present study, we aim to expand what is known about how the presence of prescribed instructional practices influences Head Start teachers' perceptions of their workplace. Attending to the perspective of the Head Start teachers tasked with complying with instructional mandates represents an important first step in understanding how these mandates function as levers to enable or encumber teachers' work. Head Start is an important context in which to study questions of instructional policy and practice as it serves children from low-income families-children who stand to benefit the most from high-quality early learning opportunities (DHHS 2008). Using a qualitative research design, the study was guided by three questions, which, together, were meant to shed light on the way that Head Start teachers perceived the program's instructional mandates:

1. How do Head Start teachers decide what to teach and how to teach?

2. How do Head Start teachers describe their primary instructional responsibilities?

3. How do Head Start teachers describe the alignment between their instruction and children's needs?

\section{Methods}

\section{Site}

We conducted this research in collaboration with a partner Head Start program. The participating Head Start organization is located within an urban area in the Northeastern United States and encompasses three cities-one larger city and two smaller ones. Sixteen centers fall under the umbrella of this Head Start organization; these Head Start centers are located in high-need communities throughout the three contiguous cities. The larger city has the highest percentage of residents living below the poverty line among all major cities ${ }^{2}$ in the state, and Latino residents constitute the largest ethnic group of people living below the poverty line in the city. Throughout the entire Head Start organization, which serves infants, toddlers, and preschool-age children (ages 0 through 6 years) in a combination of Early Head Start and Head Start programs, teachers identified $67 \%$ of the children as coming from Spanish-speaking homes (Jacoby and Lesaux 2014). Most of the Spanish-speaking families in these communities self-identify as Puerto Rican or Dominican (Jacoby and Lesaux 2014).

\footnotetext{
${ }^{2}$ For these purposes, a major city is one that has more than 100,000 residents.
} 


\section{Teachers}

Using a survey, we identified the racial/ethnic and linguistic characteristics of the 139 teachers in this Head Start organization, 136 (98\%) were women and only $3(2 \%)$ were men. Seventy-one teachers (51\%) reported their racial/ethnic identification as being Hispanic or Latino. ${ }^{3}$ The second-largest group of teachers identified themselves as White $(n=37,27 \%)$. A small proportion of teachers identified themselves as black $(n=5,4 \%)$ or multi-racial $(n=4,3 \%)$. The average years of teaching experience (i.e., all years teaching, not just years teaching in Head Start) for the lead teachers was over 14 years $(\min =3 ; \max =33 ; \mathrm{SD}=7)$. The average years of teaching in Head Start for these teachers was over 8 years $(\min =0.5 ; \max =24 ; \mathrm{SD}=6)$. The maximum level of education attained by lead teachers in this agency was completion of a graduate degree; the minimum level of education attained by lead teachers was some community college. The average level of education attained by the lead teachers was beyond an associate's degree (i.e., a 2-year degree) and less than a bachelor's degree (i.e., a 4-year degree). For this study, we interviewed a sub-sample of teachers from the entire staff.

We recruited 20 lead teachers to participate in the interviews that serve as the foundation for the analyses in the present study. All of the selected teachers identified as female, which was reflective of the $98 \%$ female staff. Twelve were English-only speakers; eight were bilingual, English-Spanish speakers. We purposively recruited teachers who worked in classrooms that enrolled a large number of dual-language learning (DLL) children because we were particularly interested in the experiences of Head Start teachers who worked with linguistically-diverse groups of children, as almost $85 \%$ of all Head Start programs enroll DLL children (DHHS 2008) and there is a need for more research on the experiences of this population of children in Head Start (DHHS 2013). The average number of years of teaching experience in Head Start for this group was 7 years $(\min =2 ; \max =17 ; \mathrm{SD}=4)$; though many of these teachers had previous teaching experience outside of Head Start, which resulted in an average total number years of teaching experience of 11 years $(\min =6 ; \max =23 ; \mathrm{SD}=5)$. Detailed information on the characteristics of the teachers and their class composition are provided in Table 1.

\section{Teacher interviews}

We conducted interviews to tap teachers' professional knowledge and practices; teachers' responses to the structured interview protocol served as the main source of data for this study. All interviews were digitally audio-recorded and transcribed verbatim, and conducted by the first author. Most interviews took about 30 min to complete. During the interview, we asked each teacher the same core set of questions regarding her work. The first set of questions asked each teacher about how they planned and implemented instruction in their classroom. We used responses gathered during this portion of the interview to answer the first and second research questions in this study, which ask how teachers describe deciding what and how to teach, and also how they prioritize their teaching responsibilities. For example, to understand how teachers made instructional decisions, we asked: "How do you decide what to do during each part of the day?" and

\footnotetext{
${ }^{3}$ Teachers also used the labels "Puerto Rican" and "Spanish" to describe their ethnic identification within this category.
} 
Table 1 Teacher characteristics and student composition in Head Start classes

\begin{tabular}{llcl}
\hline Teacher identifier & $\begin{array}{l}\text { Language(s) spoken } \\
\text { by teacher }\end{array}$ & $\begin{array}{l}\boldsymbol{N} \text { years of experience } \\
\text { teaching in Head Start }\end{array}$ & N DLL children (\% of class) \\
\hline 1 & English and Spanish & 8 & $16(89)$ \\
2 & English and French & 3 & $14(74)$ \\
3 & English & 3 & $15(79)$ \\
4 & English & 9 & $13(76)$ \\
5 & English & 3 & $12(63)$ \\
6 & English & 3 & $14(74)$ \\
7 & English & 5 & $16(84)$ \\
8 & English and Spanish & 17 & $16(84)$ \\
9 & English & 6 & $15(84)$ \\
10 & English & 13 & $14(70)$ \\
11 & English & 9 & $13(65)$ \\
12 & English and Spanish & 12 & $15(79)$ \\
13 & English and Spanish & 7 & $13(72)$ \\
14 & English & 6 & $15(79)$ \\
15 & English and Spanish & 11 & $13(68)$ \\
16 & English & 5 & $14(80)$ \\
17 & English and Spanish & 4 & $14(73)$ \\
18 & English & 2 & $12(71)$ \\
19 & English and Spanish & 3 & $15(80)$ \\
20 & English and Spanish & 2 & $13(68)$ \\
\hline DL dual language learning & &
\end{tabular}

"How much of what you do is based on what you would like to do? And how much of what you do is based on what someone else says you should do?".

The second set of interview questions pertained to a vignette about a typical, but fictional, Latino English language learning student named Juan Jose. Teachers were asked to describe how they would support the development of school-readiness skills for a child like Juan Jose, who was described to reflect a prototypical student from this Head Start program. Within this set of questions, we asked "When you think about what Juan Jose will need to be ready for kindergarten, what skills do you think are most important for him to develop?" Responses to these questions generated data that was critical to answering the third research question in this study, which asks how teachers describe the match or mismatch between their instruction and children's needs.

To understand how teachers determined what and how to teach, we coded their references to various instructional planning practices, in which they mentioned engaging. Examples of these codes include: curriculum, lesson plans, and meeting with Ed Mentors. In addition to talking about planning practices, teachers also talked about their implementation of lessons and teaching practices in the classroom. We coded features of lesson implementation and teaching, which included discussion of limitations and restrictions that teachers said regulated their implementation and practice. Examples of these teaching-related codes include: required routines, lack of time, and the in vivo code because Head Start said. Finally, we also coded their comments about responding to challenging classroom situations. We coded what kinds of challenges they encountered in their classes as well as the ways that teachers mentioned that they sought to 
address these challenges. From these codes, a primary category of challenges emerged: behavior challenges related to children's emotional outbursts. Taken together, these codes supported generating an understanding of the degree of match between instructional priorities among the Head Start agency and the Head Start teachers.

\section{Data analysis}

Within $24 \mathrm{~h}$ of conducting the interviews, the first author prepared an analytic memo for each interview, which described the context of each conversation, highlighted salient details, and captured emergent themes and questions. To facilitate the qualitative data analysis, we used QSR International's NVivo 10 software program. NVivo allowed us to move easily between transcripts and coding schemes to find patterns in the data. Working from the written transcripts, we used an open-coding process to distill prominent themes from each transcript. After we completed the first round of coding, we used a reiterative coding process to identify repeating themes across transcripts (Auerbach and Silverstein 2003; Seidman 2006).

The coding process we followed progressed from codes to categories to themes. The first author performed the first round of coding and categorization. The themes were then distilled during discussion between the two authors. Once the themes were established, member checks with early childhood educators, including Head Start teachers, were performed. From this reiterative process the final set of themes emerged.

\section{Validity and researcher positionality}

The coding of emergent themes in the teacher interview data may be subject to the authors' assumptions and biases. We, therefore, minimized the influence of any potential bias through the iterative data analysis process detailed above. We also sought the input of collaborative partners-several early childhood education researchers and practitioners-throughout the data analytic process to check assumptions and challenge conclusions.

We conducted this study within the structure of a larger program of research that was concerned with understanding the classroom contexts that serve diverse populations of low-income children in Head Start. These other studies included an observational study that measured and described the nature and quality of language and literacy instruction in participating classes (Jacoby and Lesaux 2014, 2017), and a qualitative analysis of teachers' reports of their understanding of Latino children's English language learning and their prioritization of related learning needs (Jacoby 2014). As stated previously, this paper focuses on how Head Start teachers decided what and how to teach when working within a policy context that required compliance to instructional mandates.

Though we had established a collaborative research partnership with the Head Start administration prior to embarking on this research study, we were not known to many of the teachers before the study commenced. Because the interviews were conducted at the end of the school year and as part of the larger year-long study, the first author had a familiar relationship with most of the teachers as she had observed instruction in all of their classrooms at least once prior to the interview date. All interviews were conducted in a private or semi-private location, such as an empty classroom or a teacher's 
lounge. The first author perceived that most teachers felt comfortable in her presence and answered her questions without reservation.

As authors we also acknowledge our position as White researchers from an institute of higher education in relation to the context that we were observing and studying. As noted, $40 \%$ of the early childhood teachers we interviewed identified as people of color. The majority of the children in the classes we observed came from families who identified as people of color. We have, therefore, considered how our positionality had the potential to shift participants' responses and actions, which could have contributed to biases in our findings (Milner 2007), and considered how our own racial and cultural identities contributed to our interpretation of the findings. By examining our stance as researchers and foregrounding the experiences of the study participants, we strived to represent with integrity the educational programs in which we conducted this research.

\section{Findings}

Two main findings emerged in answer to our specific research questions regarding instruction in Head Start. Additionally, a set of exceptions emerged as a third finding. First, we found that Head Start teachers reported that they taught according to required instructional routines, which they believed prevented them from being responsive to the children's needs-in part, because they perceived that the Ed Mentors required strict adherence to the routines without alteration. Second, we found that Head Start teachers believed that their primary responsibility was to develop children's social, emotional, and behavioral skills. The participating teachers also believed that children's lack of these skills derailed their instruction and that the teaching requirements restricted their ability to respond to the children's need for further support in acquiring these skills. Finally, and in contrast to statements made by the majority of the teachers, two teachers reported that they used "creativity" in planning and implementing their teaching, and thus did not feel constrained instructionally. We elaborate each of these findings in the sections that follow.

\section{Routines and compliance that limit autonomy}

Across the interviews, teachers confirmed that they taught according to mandated instructional routines and discussed how those routines affected their perceptions of their work. Teachers reported that they were required to include a set of instructional tasks in their class each day of the week, and perceived that this set of instructional tasks was required to show compliance to the Head Start mandates. As one teacher told us when she was asked to describe how she plans what to do in the class with her students, "it's mandated for us what we need to do ... Head Start incorporated it and said everybody needs to do this" (Teacher 5). In further evidence, another teacher said, "all the components are told to us by the Ed Mentors and the curriculum" (Teacher 8). In this way, the Head Start teachers perceived that the structures in place that mandated and monitored instructional components, including the curriculum, the lesson plans, and the Ed Mentors, limited their professional autonomy.

Teachers did not convey that they had decision-making authority around what to do in their classrooms with their students. Their accounts suggested that they felt there were restricted options regarding how they would spend their time in the classroom with the 
children. Another teacher explained, "We have to follow whatever the curriculum is ... We can't add all that we want or other things that the kids are interested in" (Teacher 19). Across the interviews, Head Start teachers told us that they had very little agency in planning what their daily schedule would look like in their classes.

One teacher stated that she wished she could be "more spontaneous in the classroom with the kids" but she felt hemmed in by the Head Start mandates for curricular and instructional components. "And I just kind of think it's your own thing-obviously, you're the one that spends the most time with the kids so I think it's up to the teacher to determine the best way" (Teacher 14). In this way, the instructional requirements that were handed down to Head Start teachers appeared to have eroded their sense of professional autonomy.

\section{Compromised ability to respond to children's social, emotional, and behavioral needs}

Despite the emphasis via internal policies on developing academic skills, teachers reported that their professional priority was to respond to the immediate needs of the children in their classes-and they characterized these as social, emotional, and behavioral needs (i.e., not academic needs). Teachers also reported that the time required to respond to children's immediate needs was what prevented them from getting through all required components of their lesson plans. Essentially, teachers reported that these competing obligations - to the children and to the lesson plans-were at odds with one another.

When teachers could not respond to their students' immediate needs, they felt as though they had failed in their professional responsibilities; and, when they could not get through their lesson plans-because of trying to meet the immediate needs of students - they also felt as though they had failed at their jobs. And because teachers felt unable to fulfill their professional responsibilities to either or both of these competing obligations, they did not feel successful in their work.

At the same time as feeling constrained by compliance measures, multiple teachers reported that the required instructional components were detached from their own perceptions of what the children needed or wanted. Many teachers wished that they could be more responsive and flexible during the preschool day. These teachers felt that they could perform their jobs as teachers better if they had the professional autonomy to follow their own sense of what students needed. For example, referring to the requirements to adhere to the lesson plans approved by the Ed Mentors, a teacher shared: "It seems we always have to do something ... routine things more than interacting [with the children]" (Teacher 11). Another teacher echoed this sentiment by saying that she wished she had "more time to sit with the kids and work with them" (Teacher 15).

Sixteen out of the 20 teachers we interviewed spoke about the importance of addressing children's social, emotional, and behavioral needs in the Head Start class. Most of these teachers reported that it was as important-if not more important-for their students to develop social and emotional regulation as it was to develop academic skills. As one teacher said, "I think a lot of it is social-emotional. If they don't have the social-emotional skills they're not going to be able to sit still. They're not going to be able to listen and understand. They're not going to be able to communicate" (Teacher 5). 
Because the teachers we interviewed all worked in classes that were predominantly enrolled with children learning English as a second language, many teachers juxtaposed the importance of teaching social and emotional skills with the importance of teaching English language skills. One teacher summarized, "I think the language is important, but I think the social skills are just as equally important because if you can't get along with other children, [you're] not going to be able to learn properly" (Teacher 12).

Despite the importance that the teachers placed on children's immediate needs, they frequently felt that taking time to meet children's social, emotional, and behavioral needs stole from the time they needed to get through their lesson plans. Teachers described how responding to children's immediate needs prevented them from meeting the instructional goals set forth by Head Start's required curriculum and lesson plans. One teacher, whose comments were representative of the others' responses, explained:

Some years you have really challenging kids and that prevents you from teaching altogether. Some years I feel like certain classrooms just spend their whole year on classroom management because if not, it's a safety issue. So I have been so fortunate this year. My kids are very well behaved. I don't have any major behavioral issues. We've been able to teach so much. (Teacher 4).

Another teacher explained:

Sometimes you have to be flexible; you have to go with what the kids are feeling. Sometimes you have to put all curriculum aside, just to talk about, 'oh, this is how we treat each other', or, 'this is how we use the bathroom?' So, you have to go on what the kids are needing. Yes, we have our set curriculum, but it doesn't always happen.

(Teacher 20)

One of the required instructional components that all Head Start teachers told us about was that of the daily read-aloud story. All Head Start teachers understood that they must read at least one storybook to their class of children each day. Subsequently, the teachers' lesson plans reflected this requirement, as well. Although all teachers told us that reading a storybook was a required component of daily instruction, many conceded that it might not happen if teachers were confronted with needing to address the children's social, emotional or behavioral needs. One teacher told us, "I would guess that the reason people don't read every day is if they have behavioral issues. And some classrooms have six or seven behavioral issues, where if they sit and read to the rest of the class, those kids are up and running. And it takes two of you to deal with it" (Teacher 5). Another teacher reported:

Well, the read-aloud is in the plans every day. It's just that the reason [for not doing it] could be: (1) too much going on that day; (2) depending on how the childrenbecause you go with the needs of the children, and if they're not sitting, they're not going to sit for that book. (Teacher 3)

In this way and in others, teachers conveyed that they prioritized meeting the immediate needs that the children in their classes presented to them. 


\section{Exceptions: using "creativity" to alleviate constraint}

Being held to a required set of instructional components resulted in a situation in which teachers perceived themselves to be limited in their ability to be responsive to children's needs, leading to feelings of inadequacy or failure on the part of the teachers. Notably, however, 2 of the 20 participating Head Start teachers did not perceive that the program requirements limited their ability to be an effective teacher. Contrary to what the other teachers reported, these two teachers found ways to be "creative" within the required lesson planning structure. Even though they were faced with the same requirements, their comments did not characterize the instructional mandates as restrictive, nor did they perceive the Ed Mentors as limiting their professional autonomy. One of the teachers felt that "our Education Mentor leaves it pretty open for us ... we can pretty much do whatever we want, as long as it meets the Head Start guidelines," (Teacher 6).

The other teacher, who was the most experienced teacher in our interview sample (23 years of teaching experience), noted the role of the Ed Mentor as an overseer of classroom instruction. In contrast to the majority of the Head Start teachers, however, she did not report feeling limited by the examination of her instruction or the requirements for compliance with the lesson plans. As she said:

So we need to follow the form of that [the daily lesson plans], but we can be creative. We can make our own ideas. And also, the Ed Mentor is coming to my room. And she is always looking through my lesson plan. And then, if she says that I need something more, she can give me a plan or a new idea. So that way I can develop a better lesson plan. But yes, I need to follow the schedule. (Teacher 8)

These teachers both acknowledged that they were required to follow Head Start's instructional mandates; yet, they viewed them as being supportive rather than punitive. These teachers found a way to maintain a sense of professional autonomy while also complying with the instructional mandates, while most others seemed unable to reconcile these two competing interests: following the strict guidelines for lesson planning and instruction, and meeting their students' needs.

\section{Discussion and implications}

In this study, in an effort to understand how preschool teachers perceive instructional mandates, we interviewed 20 early education teachers from Head Start, the US federally sponsored preschool program for children from low-income families. These teachers were charged with creating high-quality learning environments in large part through the use of instructional routines, curricula, and lesson plans that matched a set of national program performance standards. Building upon a research base focused on the experiences of teachers in K-12 systems, we sought to uncover the ways in which Head Start teachers' perceive these instructional responsibilities-as dictated by the instructional mandates they received. The findings surface what appears to be a dilemma for teachers in their daily work.

That is, teachers in our study reported that the program's requirements around use of instructional time in their classes were frequently at odds with their perceived immediate needs of the children in the classes. Like Head Start teachers in prior investigations (Hollingsworth and Winter 2013; Kowalski et al. 2001), these teachers cited developing 
children's social, emotional, and regulatory skills as being as important as-or sometimes more important than-developing early academic skills through curriculum-based lessons. And because the teachers placed such a high priority on meeting children's immediate needs and developing their social, emotional, and behavioral skills that they felt would support future school success, most teachers found "fitting in" all the required components of their curriculum and lesson plans was a difficult and competing task.

To understand this reported conundrum-how the instructional mandates that were intended to support teachers' work could function instead as roadblocks that prevented them from feeling a sense of autonomy in their work-we employ a theoretical framework informed by research in US K-12 schools. Specifically, this framework comes from Rosenholtz's (1989) research on teaching cultures. Rosenholtz describes how teaching cultures in K-12 schools varied in terms of how routine or nonroutine teachers perceived the prescriptive instructional practices in their workplace culture. ${ }^{4}$ Routine teaching cultures were characterized by highly prescriptive instructional practices that teachers perceived as limiting their ability to respond to students' needs. For example, teachers in Rosenholtz's study who perceived their workplace culture as routine described their schools as employing a one-size-fits-all approach to remediating difficulties or responding to challenges. In contrast, within a nonroutine school culture teachers perceived that they had more discretion to examine the needs of their students and deliver their instruction to respond to these needs.

In Rosenholtz's (1989) study, as in our work in Head Start, the establishment of a routine teaching culture can be understood to come from an organizational perspective that desires to help teachers. Essentially, to support teachers, some school systems, whether serving young children or adolescents, may prescribe the use of specific practices, curriculums, and teaching strategies. The intent of these actions is to codify the program's beliefs regarding "best practice" into the routine of teaching in that school. When these practices are integrated into the routine teaching of the workplace, the presumption is that teachers will both feel more effective and teach more effectively.

Counter to this operating assumption, Rosenholtz (1989) found that a highly routinized school culture that demanded adherence to set instructional requirements limited a teacher's range of responses and, therefore, exacerbated their uncertainty that they were meeting their students' needs. For the teachers Rosenholtz studied in elementary schools, feelings of efficacy were tied to whether or not the instructional routines allowed them to respond to the challenges they faced in their work with children. Indeed, Rosenholtz explained that what she referred to as the "degree of certainty" teachers felt about their work-how effective teachers perceived they were in meeting students' needs-was directly linked to the nonroutine teaching culture of their school.

We found a similar perception among the teachers we interviewed. That is, most participating Head Start teachers felt that being required to comply with set teaching routines prevented them from adequately addressing their students' needs. The routine

\footnotetext{
${ }^{4}$ Importantly, Rosenholtz's concept of a routine teaching culture is not equated with the early childhood teaching practice of using teaching "routines." Early childhood teachers frequently use "routines," such as the Calendar Routine or the Morning Meeting Routine, in their classes to establish a structure that is predictable and reliable for their young students. Rosenholtz's framework is not meant to invoke this concept of teaching with routines. Rather, Rosenholtz used the terms routine and nonroutine to characterize the teaching culture in the schools she studied-not to describe the implementation technique of the specific teaching practices.
} 
teaching culture in Head Start-meaning that that certain activities and teaching strategies were prescribed during instructional time-was not perceived of as responsive to the immediate needs that teachers faced in their work. Like the teachers in Rosenholtz's (1989) study, the Head Start teachers we interviewed did not perceive the required routine components of their workplace as responsive to the demands of their work.

Given the program's mission and design, Head Start teachers have long been steadfast advocates of the importance of developing their students' skills in the social, emotional, and behavioral domains. Multiple studies have documented the high priority that Head Start teachers, and other preschool teachers, report placing on social and emotional skill development (Hollingsworth and Winter 2013; Kowalski et al. 2001; Zinsser et al. 2014). Interestingly, this priority on social, emotional, and behavioral skill development is not just reported as being high-it is reported as being higher than the priority given to academic skill development (Hollingsworth and Winter 2013; Kowalski et al. 2001). This relationship is mirrored in the research that demonstrates that the healthy development of social and emotional skills is related to positive outcomes in academic achievement, as well as the prosocial development of other interpersonal skills and abilities (Jones and Bouffard 2012). In that sense, Head Start teachers may not need to be convinced of the importance of including opportunities for children to work on their social, emotional, and behavioral skills in the context of the class and are appropriately committed to these goals. What may be missing for Head Start teachers, however, is an explicit statement encouraging the development of academic and social and emotional skills in tandemand/or providing more professional education on the ways in which these developing skills fuel one another-perhaps even through the same instructional mandates. Indeed, prior research demonstrates that these initiatives can be successful in developing both academic skills and social and emotional skills at the same time (Bierman et al. 2008; Jones et al. 2011).

The implications of the Head Start scenario are worthy of consideration, particularly given today's context of early education. From research in US K-12 schools we know that teachers' perceptions of their workplace influence their decisions to stay or leave their jobs and their overall satisfaction with their jobs (Bryk et al. 2010; Johnson et al. 2012; Ladd 2009). Importantly, teachers' perceptions of their workplace also have a direct relationship to their students' academic achievement (Johnson et al. 2012). Though research about teacher retention and satisfaction in preschool programs is limited, recent research suggests this also appears to be true for Head Start teachers. A recent study found that newly hired Head Start teachers who left their job after only a few months reported that their dissatisfaction with their work environment was a major factor in that decision (Wells 2015). Teacher retention and satisfaction are crucial to the Head Start model because a consistent and positive adult presence supports the kind of development that is critical to children's later academic achievement (Shonkoff and Phillips 2000). Other researchers have noted the importance of a positive workplace climate for teachers; the prosocial classroom model (Jennings and Greenberg 2009) provides a theoretical framework for understanding how teachers' own social and emotional wellbeing translates into improved classroom learning and interactions for students. This framework also suggests that supporting teachers' social and emotional competence in the workplace could reduce burn-out and improve retention. Finally, our finding that the 
most experienced teacher felt that she could be creative and effective within the instructional mandates suggest another benefit of retaining teachers in Head Start. For these reasons and others, including the time and expense involved with hiring and training new teachers, early childhood care and education programs ought to be concerned with how teachers perceive their workplace conditions so that they can preserve an experienced and stable teaching staff.

Thus, based on the findings discussed above, we identify important implications for policy-makers, education practitioners and education researchers. The first set of implications we discuss relates to policy and practice; the second relates to the need for future research that continues to seek out and amplify the voices of early childhood teachers within the empirical knowledge base.

\section{Implications for US policy and practice}

We enter into this work with the guiding belief that all Head Start policy, whether in the domain of health and safety or learning and development, exists to ensure that the population it serves achieves the best possible outcomes. In addition, we believe that the instructional mandates Head Start teachers receive, such as to comply with specified teaching routines, curricula, or lesson plans, were created by drawing upon a solid foundation of research in early childhood learning and development. Our findings suggest, however, that instead of supporting teachers' sense of professional efficacy and autonomy, in reality, the instructional mandates have an inverse effect.

In our study, instructional mandates were not perceived by teachers as being relevant or responsive to the needs of the children. By way of implications, then, there are several to consider that might alter this perception. For example, allowing Head Start teaching teams to adapt instructional guidelines to reflect the needs of their local population of learners (e.g., to further consider linguistic or cultural diversity, or degree of adverse experience) might improve teachers' dispositions towards the guidelines and increase their willingness to implement these practices. Instead of attenuating teachers' sense of professional control over what they teach, as the current instructional mandates were reported to do, policy that allows for built-in local adaptations could improve teachers' sense that they could meet required guidelines and adapt them to fit their own instructional plans. Not only would local-level flexibility in policy perhaps improve teacher buy-in, it would also enhance the ability of any given policy to respond effectively to the particularities of the local context, and in so doing, better meet their goals for child learning and development.

As stated above, we presume that most-if not all - of the curricular and instructional components that Head Start teachers were required to incorporate in their teaching are based on best practice as supported by early childhood research. Therefore, what we see as an implication of our study is that local-level Head Start teams need to be supported and encouraged to adapt national program standards to respond to local-level needs. Notably, the first complete revision and reorganization of the Head Start Program Performance Standards since 1975 was recently released for implementation in November 2016 (DHHS 2016). One component of this revision was an increased emphasis on teacher development and support (Kaplan and Mead 2017). Though it is too early to evaluate how these revised performance standards will affect the nature and quality of 
instruction in Head Start classrooms, they have raised awareness of the importance of attending to teacher development using mechanisms such as coaching and professional training. This new emphasis on teacher development opens the door to opportunities to support teachers in adapting the federal policy to be responsive to their local needs.

We also see an important opportunity for targeted professional development for Head Start teachers around the program's instructional mandates. We found that the most experienced participating teacher, as well as a second, less-experienced teacher, did not share the sense that the instructional mandates for academic skill development conflicted with the children's need to develop social, emotional, and behavioral skills. These interviews suggested that what these teachers possessed was a greater level of understanding of-and possibly comfort with-the content of the instructional mandates. These teachers may have been able to see the relationship between good instructional practice and opportunities to promote social and emotional development more easily than their peers. From prior research (see Jones and Bouffard 2012), we know that the integration of academic learning and social and emotional learning ought to be a cornerstone of high-quality early education programs. An additional implication from this study, therefore, is that providing professional development around the content and intended implementation of the instructional mandates might aid Head Start teachers in drawing the link between the required academic routines and the social and emotional learning needs of their students.

Finally, professional development and peer-collaboration opportunities that open up pathways of communication between teachers who share contrasting views of the instructional mandates could also be effective for reducing the feeling of constraint for many. Indeed, we did identify knowledge and expertise within the teaching staff that could be leveraged to support others within the same program to work more effectively with the mandates.

\section{Implications for research}

A second set of implications that arise from this study relates to the work of education researchers. That is, more research is needed to increase the theoretical and empirical understanding of how policy affects teaching and learning in early childhood education settings. Most of the past research regarding how policy influences teachers' perceptions of their work in the US has been conducted in K-12 settings. The prior research from K-12 settings can help shed light on the issues that may affect early childhood education contexts and their teachers; however, as noted previously, there are many important distinctions between the K-12 and early childhood systems that limit the application of the prior work, including issues of training and credentialing, and compensation, as well as a more linguistically and culturally diverse workforce.

To that end, drawing on the research conducted with K-12 teachers provides an inaccurate view of the challenges and opportunities in the early childhood teaching context. Instead, we suggest that future studies ought to investigate how these unique features of early childhood education programs-including Head Start-contribute to the perceptions and actions of the teachers within their workplace. We also suggest that future research -and in particular, research that aims to influence early childhood education policy-ought to include the unique voices of Head Start teachers. 
Finally, in addition to the voices of the Head Start teachers, which we foregrounded in this study, future research investigations should include the voices of the other adults in these classrooms who play an important role in program delivery: namely, the assistant teachers and the Ed Mentors. As other scholars have noted, the role of assistant teachers in early childhood education classes has been largely overlooked (e.g., Sawyer et al. 2016; Sosinsky and Gilliam 2011), and given our findings in relation to the Ed Mentors, the perspectives of these administrative personnel who mentor and coach these teachers could also have a voice in future research investigations.

\section{Limitations}

As with any investigation, there may be limitations to the generalization of the findings presented in this study to other educational contexts. Though our sample size of 20 teachers is similar to or larger than (e.g., Sofou and Tsafos 2009) that of other interview studies in education, we recognize that increased variation in responses may have been found had we interviewed additional Head Start teachers. Furthermore, we interviewed Head Start teachers who worked in classes with low-income DLL children and thus, our results may be limited in generalizability to other Head Start contexts that also enroll DLL children. Notably, about $85 \%$ of all Head Start classrooms enroll DLL children (DHHS 2008); therefore, we believe that these findings will be relevant to the majority of US Head Start programs. Finally, based on the rigor of the methods we followed, we trust that teachers in our interview study responded honestly to the questions asked. We cannot know if they viewed the interview as an opportunity to vent frustration. Despite the potential for this type of threat to validity, we believe that the rapport we established with the teachers over the school year and the ubiquity of some of the themes shared during the interviews speaks to the professionalism and honesty with which the teachers approached their participation in this research study.

\section{Conclusion}

In this study, we demonstrated that policy-related instructional mandates in an early childhood program conflicted with teachers' perceptions of what children needed and compromised their sense of professional autonomy. These findings build upon an emerging foundation of research conducted in early childhood education settings (e.g., Brodin and Renblad 2015; Bullough et al. 2014; Sofou and Tsafos 2009; Wood 2004). Both practical and research-related implications emerge from this work. One implication is aimed at all governments that are contemplating how to support early learning through the expansion of government-funded preschool programs, in particular those that have national curriculums in place. Even if the national curriculums are designed to allow for local flexibility, the perception of the rigidity of these curriculums as reported by the teachers who implement them ought to be considered a priori, particularly when designing professional training and support prior to implementation. Findings from the present study suggest that the intended message-as set forth by the policy-makers-and the received message-as interpreted by the teachers-may be different. The second implication is aimed at the research community and suggests that the voices of early childhood educators ought to be more present in investigations into the quality of early education programs. These voices are reflected only infrequently in the research 
literature, yet they enrich our understanding of how to design and achieve the best possible learning environments for young children across the globe.

\section{Authors' contributions}

JWJ conceived of and carried out the study; performed the analyses and drafted the manuscript. NKL participated in the design of the study; supervised the analysis process and helped draft the manuscript. Both authors read and approved the final manuscript.

\section{Authors' information}

JWJ is the Class of 1929 Dr. Virginia Apgar Assistant Professor of Education at Mount Holyoke College. She uses qualitative and quantitative methods to study the development of both teachers and children in early childhood education programs. She is particularly concerned with understanding how local and national policies support high-quality teaching in schools that serve culturally and linguistically diverse groups of children. NKL is the Juliana W. and William Foss Thompson Professor of Education and Society at the Harvard Graduate School of Education. Her research focuses on promoting the language and literacy skills of today's children from diverse linguistic, cultural and economic backgrounds, and is conducted largely in urban and semi-urban cities and school districts.

\section{Author details}

${ }^{1}$ Department of Psychology and Education, Mount Holyoke College, South Hadley, MA 01075, USA. ${ }^{2}$ Harvard Graduate School of Education, Cambridge, MA, USA.

\section{Competing interests}

The authors declare that they have no competing interests.

\section{Compliance with ethical guidelines}

All participants provided Informed Consent prior to taking part in the study. All components of the research study were reviewed and approved by Harvard's Committee on the Use of Human Subjects, which serves as the Institutional Review Board at Harvard University.

\section{Funding}

There are no funding sources to disclose.

\section{Publisher's Note}

Springer Nature remains neutral with regard to jurisdictional claims in published maps and institutional affiliations.

Received: 17 January 2017 Accepted: 14 September 2017

Published online: 20 September 2017

\section{References}

Alvestad, M., \& Samuelsson, I. P. (1999). A comparison of the national preschool curricula in Norway and Sweden. Early Childhood Research \& Practice, 1(2). Retrieved from http://ecrp.uiuc.edu/v1n2/alvestad.html.

Auerbach, C. F., \& Silverstein, L. B. (2003). Qualitative data: An introduction to coding and analysis. New York: New York University Press.

Barnett, W. S., Friedman-Krauss, A. H., Gomez, R. E., Horowitz, M., Weisenfeld, G. G., Brown, K. D., et al. (2016). The state of preschool 2015: State preschool yearbook. New Brunswick, NJ: National Institute for Early Education Research.

Bierman, K. L., Domitrovich, C. E., Nix, R. L., Gest, S. D., Welsh, J. A., Greenberg, M. T., et al. (2008). Promoting academic and social-emotional school readiness: The Head Start REDI program. Child Development, 79, 1802-1817. doi:10.1111/j.1467-8624.2008.01227.x.

Brodin, J., \& Renblad, K. (2015). Early childhood educators' perspectives of the Swedish national curriculum for preschool and quality work. Early Childhood Education Journal, 43(5), 347-365.

Bryk, A., Sebring, P. B., Allensworth, E., Luppescu, S., \& Easton, J. (2010). Organizing schools for improvement: Lessons from Chicago. Chicago: University of Chicago Press.

Bullough, R. V., Hall-Kenyon, K. M., MacKay, K. L., \& Marshall, E. E. (2014). Head Start and the intensification of teaching in early childhood education. Teaching and Teacher Education, 37, 55-63.

Chandler, M. A. (2014). Finland working to expand early education. The Washington Post. Retrieved from https://www washingtonpost.com/local/education/finland-working-to-expand-early-education/2014/03/04/571aacf8-a3ba11e3-8466-d34c451760b9_story.html.

Deming, D. (2009). Early childhood intervention and life-cycle skill development: Evidence from head start. American Economic Journal: Applied Economics, 1(3), 111-134.

Ede, A. (2006). Scripted curriculum: Is it a prescription for success? Childhood Education, 83(1), 29-32.

Flottman, R., \& Page, J. (2012). Getting early childhood onto the reform agenda: An Australian case study. International Journal of Child Care and Education Policy, 6(1), 17-33.

Gormley, W. T., \& Phillips, D. (2005). The effects of universal pre-k in Oklahoma: Research highlights and policy implications. Policy Studies Journal, 33(1), 65-82.

Heckman, J. J., \& Masterov, D. V. (2007). The productivity argument for investing in young children. Applied Economic Perspectives and Policy, 29(3), 446-493.

Hollingsworth, H. L., \& Winter, M. K. (2013). Teacher beliefs and practices relating to development in preschool: Importance placed on social-emotional behaviours and skills. Early Child Development and Care, 183(12), 1758-1781. 
Jacoby, J. W. (2014). Teaching and working in linguistically diverse early childhood education programs: Three studies in Head Start (Doctoral dissertation). Available from ProQuest Dissertations Publishing. (UMI No. 3662084).

Jacoby, J. W., \& Lesaux, N. K. (2014). Support for extended discourse in teacher talk with linguistically diverse preschoolers. Early Education and Development, 25(8), 1162-1179. doi:10.1080/10409289.2014.907695.

Jacoby, J. W., \& Lesaux, N. K. (2017). Language and literacy instruction in preschool classes that serve Latino dual language learners. Early Childhood Research Quarterly, 40, 77-86. doi:10.1016/j.ecresq.2016.10.001.

Jennings, P. A., \& Greenberg, M. T. (2009). The prosocial classroom: Teacher social and emotional competence in relation to student and classroom outcomes. Review of Educational Research, 79(1), 491-525.

Johnson, S. M., Kraft, M. A., \& Papay, J. P. (2012). How context matters in high-need schools: The effects of teachers' working conditions on their professional satisfaction and their students' achievement. Teachers College Record, 114, 1-39.

Jones, S. M., \& Bouffard, S. M. (2012). Social and emotional learning in schools: From programs to strategies. Social Policy Report. Volume 26, Number 4. Society for Research in Child Development.

Jones, S. M., Brown, J. L., \& Aber, L. J. (2011). Two-year impacts of a Universal School-Based Social-Emotional and Literacy Intervention: An experiment in translational developmental research. Child Development, 82, 533-554. doi:10.1111/j.1467-8624.2010.01560.x.

Kaplan, M. \& Mead, S. (2017). The best teachers for our littlest learners?: Lessons from Head Start's last decade. Retrieved from Bellwether Education Partners website: https://bellwethereducation.org/sites/default/files/Bellwether_HeadStartWorkforce.pdf.

Kowalski, K., Pretti-Frontczak, K., \& Johnson, L. (2001). Preschool teachers' beliefs concerning the importance of various developmental skills and abilities. Journal of Research in Childhood Education, 16, 5-14.

Ladd, H. (2009). Teachers' perceptions of their working conditions: How predictive of policy relevant outcomes? (Working Paper No. 33). Washington, DC: National Center for Analysis of Longitudinal Data in Education. Retrieved April 21, 2014, from http://www.urban.org/uploadedpdf/1001440-Teachers-Perceptions.pdf.

Ludwig, J., \& Phillips, D. A. (2008). Long-term effects of Head Start on low-income children. Annals of the New York Academy of Sciences, 1136(1), 257-268.

Mancilla-Martinez, J., \& Lesaux, N. K. (2014). Promoting shared cultural and linguistic backgrounds among children and families in Early Head Start/Head Start programs. Dialog, 17(3), 35-48.

May, H. (2008). Towards the right of New Zealand children for free early childhood education. International Journal of Child Care and Education Policy, 2(1), 77-91.

Milner, H. R. (2007). Race, culture, and researcher positionality: Working through dangers seen, unseen, and unforeseen. Educational Researcher, 36(7), 388-400.

Neuman, S. B., \& Cunningham, L. (2009). The impact of professional development and coaching on early language and literacy instructional practices. American Educational Research Journal, 46(2), 532-566.

Parks, A. N., \& Bridges-Rhoads, S. (2012). Overly scripted: Exploring the impact of a scripted literacy curriculum on a preschool teacher's instructional practices in mathematics. Journal of Research in Childhood Education, 26(3), 308-324.

Rosenholtz, S. J. (1989). Teachers' workplace: The social organization of schools. White Plains, NY: Longman Inc.

Saluja, G., Early, D. M., \& Clifford, R. M. (2002). Demographic characteristics of early childhood teachers and structural elements of early care and education in the United States. Early Childhood Research \& Practice, 4(1), 1-19.

Sawyer, B. E., Atkins-Burnett, S., Hammer, C. S., Komaroff, E., Sandilos, L., Lopez, L., \& Blair, C. (2016). Variations in classroom language environments of preschool children who are low-income and linguistically diverse. Paper presented at the 2016 American Educational Research Association Conference Meeting, Washington, DC.

Seidman, I. (2006). Interviewing as qualitative research: A guide for researchers in education and the social sciences (3rd ed.). New York: Teachers College Press.

Shonkoff, J. P., \& Phillips, D. A. (2000). From neurons to neighborhoods: The science of early childhood development. Washington, DC: National Academy Press.

Sofou, E., \&Tsafos, V. (2009). Preschool teachers' understandings of the national preschool curriculum in Greece. Early Childhood Education Journal, 37, 411-420.

Sosinsky, L. S., \& Gilliam, W. S. (2011). Assistant teachers in prekindergarten programs: What roles do lead teachers feel assistants play in classroom management and teaching? Early Education and Development, 22(4), 676-706.

Taguma, M., Litjens, I., \& Makowiecki, K. (2012). Quality matters in early childhood education and care: New Zealand 2012. OECD Publishing. doi:10.1787/9789264176690-en.

US Department of Health and Human Services. (2008). Dual language learning: What does it take? Head Start dual language report. Washington, DC: US Department of Health and Human Services.

US Department of Health and Human Services. (2016). Head Start program performance standards. Washington, D.C.: US Department of Health and Human Services. Retrieved from: http://eclkc.ohs.acf.hhs.gov/policy/presenting.

US Department of Health and Human Services, Administration for Children and Families. (2010). Head Start impact study: Final report. Washington, DC: US Department of Health and Human Services, Administration for Children and Families.

US Department of Health and Human Services, Administration for Children and Families. (2013). Report to congress on dual language learners in Head Start and early Head Start programs. Washington, DC: US Department of Health and Human Services, Administration for Children and Families. Retrieved from: http://www.acf.hhs.gov/sites/default/ files/opre/report_to_congress.pdf.

Wasik, B. A., Bond, M. A., \& Hindman, A. (2006). The effects of a language and literacy intervention on Head Start children and teachers. Journal of Educational Psychology, 98(1), 63-74.

Weiland, C., \& Yoshikawa, H. (2013). Impacts of a prekindergarten program on children's mathematics, language, literacy, executive function, and emotional skills. Child Development, 84(6), 2112-2130.

Wells, M. B. (2015). Predicting preschool teacher retention and turnover in newly hired Head Start teachers across the first half of the school year. Early Childhood Research Quarterly, 30, 152-159.

Whitebook, M., Phillips, D., \& Howes, C. (2014). Worthy work, STILL unlivable wages: The early childhood workforce 25 years after the National Child Care Staffing Study. Berkeley, CA: Center for the Study of Child Care Employment, University of California, Berkeley. 
Wood, E. (2004). A new paradigm war? The impact of national curriculum policies on early childhood teachers' thinking and classroom practice. Teaching and Teacher Education, 20, 361-374.

Zinsser, K. M., Shewark, E. A., Denham, S. A., \& Curby, T. W. (2014). A mixed-method examination of preschool teacher beliefs about social-emotional learning and relations to observed emotional support. Infant and Child Development, 23(5), 471-493.

Submit your manuscript to a SpringerOpen ${ }^{\circ}$ journal and benefit from:

- Convenient online submission

- Rigorous peer review

- Open access: articles freely available online

- High visibility within the field

- Retaining the copyright to your article

Submit your next manuscript at $>$ springeropen.com 